\title{
Dos trágicas trombosis puerperales: Paula Modersohn-Becker y María Estuardo
}

\author{
Two tragic puerperal thrombosis: \\ Paula Modersohn-Becker and Mary Stuart
}

"Las mujeres no pueden ser pintoras". Con estas desalentadoras palabras de su padre se abre la película "Paula", del director alemán Christian Schwochow, estrenada en España en junio-2017 1,2. Reconstrucción biográfica de primorosa factura de la pintora de Bremen Paula Modersohn-Becker (1876-1907), en ella también tiene que soportar "las mujeres nunca concebirán nada creativo, excepto hijos" que le espeta el pintor Fritz Mackensen, su profesor. Toda su vida intentará probar que se equivocan. Unas 750 pinturas y un millar de dibujos lo demostrarán largamente. Pero la escena final, antes de que, casi sobre los títulos de crédito, Paula nos muestre algunas de sus obras más representativas, es sobrecogedora. Tras abandonar su querido París, regresar al entorno rural de Worpswede, haber superado sus temores sobre la maternidad y dar a luz a su anhelada hija Tillie, Paula se desploma súbitamente, susurrando con un último aliento "Qué lástima". Muere de un embolismo pulmonar (EP) a los 18 días tras el parto. Tiene 31 años $^{3}$.

Haciendo gala de su independencia, a los 24 años se había presentado en la comunidad de artistas de Worpswede, cerca de Bremen, para recibir clases de Mackensen, entonces factótum del Art Nouveau, de inmenso éxito en la Alemania de fines del siglo XIX. Allí muestra su independencia, aportando su propia visión y negándose a la copia servil de la naturaleza. En Worpswede se casará con el pintor viudo Otto Modersohn. Pasa años intentando adaptarse a la vida rural, aunque frustrada por el exiguo reconocimiento y atormentada por los celos profesionales de su marido y la insatisfactoria relación con este, que se negaba a las relaciones sexuales por miedo a que ella falleciera al dar a luz, como su primera mujer. Alentada por el poeta Rilke y su esposa -su amiga, la escultora Clara Westhoff-, marcha a París, huyendo de aquel ambiente asfixiante. Alli vive liberalmente el amor, pero, sobre todo, tras descubrir a Cézanne y Gauguin, libera su pintura. Con un estilo entre expresionista y "fauve", nunca jamás en el arte se había representado el cuerpo de la mujer, incluyendo su propio cuerpo desnudo, como lo hizo Modersohn-Becker ${ }^{3}$. (Fig. 1). Sólo mucho más tarde vendrán las doloridas obras de Frida Kahlo, artista con la que comparte singulares afinidades: nacida una el año de muerte de la otra, autorretratos, anhelos de maternidad y prematuro fallecimiento, atribuido en ambas a EP. Asustado, su propio marido
Fig 1. Paula Modersohn-Becker. Autorretrato con camelias (1907). Con su hija, Tillie, recién nacida. (Dominio público y Wikipedia Commons).
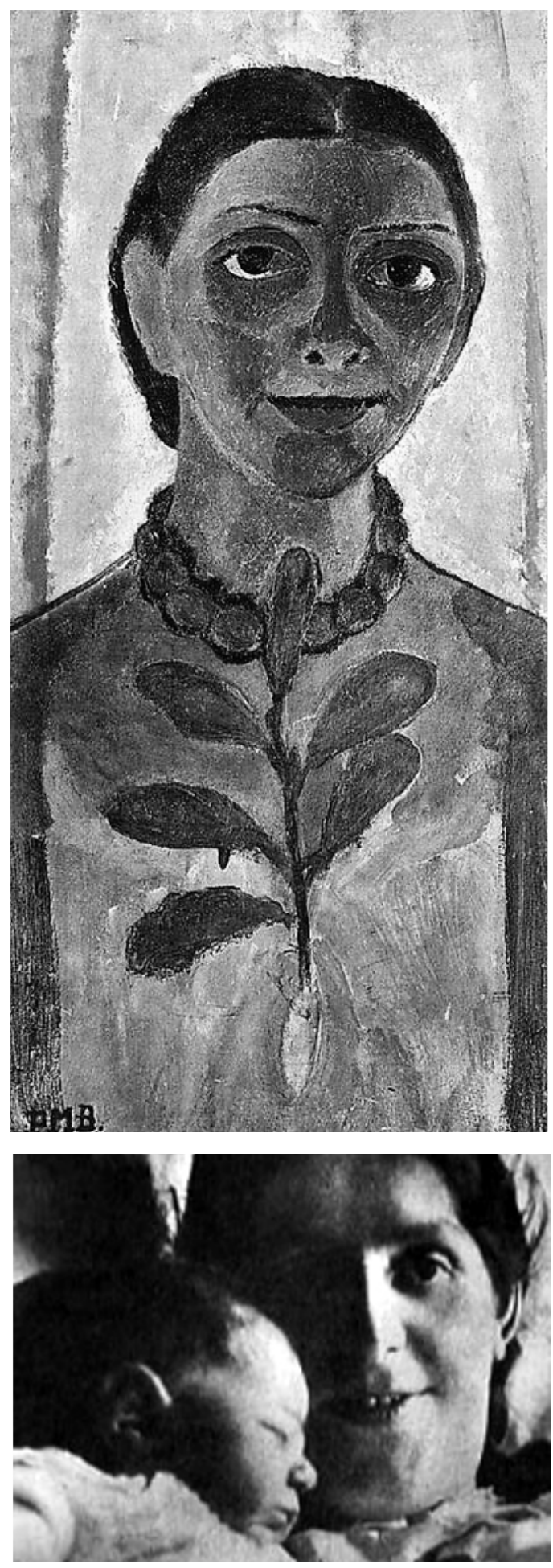
la amenaza con internarla en una institución mental, aunque al final desistirá. $Y$ a la postre, logrado ya un lenguaje propio, -"Siento que se acerca el momento en el que ya no tenga que avergonzarme y quedarme callada, sino que sienta con orgullo que soy una pintora", escribe a su madre, poco antes de morir ${ }^{1}-$, accede a retornar con su marido a Worpswede, cumple sus deseos largamente pospuestos de maternidad, pero fallece inesperadamente. Por mucho tiempo será la única mujer con un museo monográfico dedicado a su obra (Bremen).

También la vida de María Estuardo, "Reina de los Escoceses", acabará dramáticamente a los 44 años, tras su decapitación ordenada por Isabel I. Pero antes padecerá las secuelas de una trombosis venosa puerperal en el parto gemelar ocurrido tras aquel del que naciera el futuro rey inglés Jacobo I. Un síndrome postflebítico, junto con achaques poco esclarecidos -dolor abdominal, vómitos, irritabilidad/depresión, artritis...-, atribuidos a procesos varios -porfiria, artritis reumatoide...- provocarán intensos sufrimientos que la forzarán a utilizar bastones y ayuda de asistentes hasta su ejecución ${ }^{4}$.

Podría aducirse que tales ejemplos históricos son reliquias de tiempos pasados. Sin embargo, las cifras recientes de que la mortalidad materna relacionada con el embarazo está aumentando en EEUU, a diferencia de otros países ${ }^{5}$, y que el EP supone la $5^{\mathrm{a}}$ causa de dichas muertes $(9,5 \%)^{6}$ suponen rotundas rectificaciones a tal aserción. Siguen siendo, pues, precisas medidas adecuadas para que tragedias como las de Paula Modersohn-Becker o sufrimientos como los de María Estuardo, puedan evitarse en tiempos actuales? El reciente y grave EP sufrido por la tenista Serena Williams tras el parto de su primer hijo constituyen otro dramático aldabonazo. (El Mundo, 21/02/2018).

\section{Bibliografía}

1. Medina M. Paula Modersohn, la artista irreverente que escandalizó a la puritana Alemania. El Confidencial,26/05/217. Disponible:http://www.elconfidencial.com/ cultura/cine/2017-05-26/paula-modernsohn-pintora-cine-biografia_1387801 [acceso, 15/08/2017].

2. Zurro J. Paula Becker, la pintora que retrató el machismo del mundo del arte. El Español, 26/05/2017. Disponible: http://www.elespanol.com/cultura/ cine/20170525/218728706_0.html [acceso, 15/08/2017].

3. Radycki D. Pictures of Flesh: Modersohn-Becker and the Nude. Woman's Art J. 2009; 30 (2): 3-14.

4. MacNalty A. The maladies of Mary Queen of Scots. Med Hist. 1961; 5(3): 203-9. Disponible:http://www.ncbi.nlm.nih.gov/pmc/articles/PMC1034624 [acceso,
[ 15/07/2017].

5. Kassebaum NJ et al. Global, regional, and national levels and causes of maternal mortality during 1990-2013: a systematic analysis for the Global Burden of Disease Study 2013. Lancet 2014; 384: 980-1004.

6. Report from Maternal Mortality Review Committees: A view into their critical role. Feb, 2017.Disponible:_http://www.cdcfoundation.org/sites/default/files/upload/pdf/ MMRIAReport.pdf. [acceso, 15/08/2017].

7. Fontcuberta J (coord.). Trombosis en la mujer. Aspectos prácticos. Acción Médica: Madrid; 2012. 207 pp.

Julio Montes-Santiago

Complejo Hospitalario Universitario. Vigo 